\title{
Baseline Survey of New Medical Undergraduates: Profile and Potential for Follow-Up
}

\author{
de Abrew, A. ${ }^{1}$, Karunathilake, I.M. ${ }^{2} \&$ Perera, J. ${ }^{3}$
}

\begin{abstract}
Background: The Faculty of Medicine, University of Colombo is one of the foremost institutes providing Medical Education in Sri Lanka. Many factors affect academic performance of medical undergraduates, including admission scores, personality, gender, English language ability, coping skills and availability of academic and social support.
\end{abstract}

Objectives: To profile and quantify selected factors that may predict academic performance among medical undergraduates.

Methods: A descriptive cross-sectional study was carried out on new entrants. A structured selfadministered questionnaire collected data on demographic characteristics, previous academic performance, extra-curricular activities, residence and travel, English and Information Technology (IT) competency.

Results: Details were obtained of 198 students, including 8 (4\%) foreign students. Average age was 22.1 years with a female preponderance of $55 \%$. Most $(63 \%, n=124)$ had entered at the first attempt, with all enrolments on merit. While over one third $(n=72)$ entered from the Colombo District, only 44 were permanent residents. Participation in extra-curricular activities was reported by $42 \%$. Most $(n=117)$ had obtained an "A" grade at the General English examination, and reported average to high English language competency. However, only 34 (17\%) reported high competence in listening comprehension. Almost all (99.5\%) had a mobile phone and most reported familiarity with simple IT based tasks.

Conclusions: New entrants demonstrate high rates of conventionally recognised predictors of academic success such as entry at first attempt, female gender and English proficiency. There is a need to explore the use of these and other non-cognitive factors to identify students who may be at risk of poor academic performance and offer early remedial intervention.

Keywords: Medical Students, Medical Education, Sri Lanka

\section{Background}

Since its inception in 1870, the Faculty of Medicine, University of Colombo has been in the forefront of medical education in Sri Lanka.

\footnotetext{
${ }^{1}$ Lecturer, Department of Medical Education, Faculty of Medicine, University of Colombo.

${ }^{2}$ Head, Department of Medical Education, Faculty of Medicine, University of Colombo.

${ }^{3}$ Dean, Faculty of Medicine, University of Colombo.

Corresponding author:

Dr. A de Abrew,

Department of Medical Education, Faculty of Medicine, No.25, Kynsey Road, Colombo 0800, Sri Lanka

Email: ashwinie@medarc.cmb.ac.lk
}

Although its beginnings as the Ceylon Medical School were modest, with just three teachers and 25 students, it rapidly progressed to the status of a College in 1880, and was incorporated to the University of Ceylon as the Faculty of Medicine in 1942. With this change, the initial Licentiate of Medicine and Surgery (LMS) became the MBBS degree (University of Colombo, 2008; Faculty of Medicine, 2016). In keeping with the ever widening horizons in medicine and innovations in medical education, a new integrated curriculum was adopted in 1995, after six years of planning. Since then, 16 batches of students have graduated from the Colombo Medical Faculty, at the rate of approximately 200 students per year. 
In accordance with Subject Benchmark Statement in Medicine published by the University Grants Commission (UGC), Sri Lanka, the Faculty offers a MBBS degree programme of 5 years' duration, with a curriculum that promotes the acquisition of desired knowledge, skills and attitudes through student centred learning methods (UGC, 2004). At present, the Faculty has approximately one thousand students registered for the undergraduate degree programme in Medicine, and approximately 130 full time academic staff members (Faculty of Medicine, 2016).

A career in medicine has been considered more challenging compared to other fields of professional study, due to longer and emotionally demanding training as well as high performance expectations (Waghachavare et al., 2013; Guthrie et al., 1998). Academic workload, high stakes examinations, competition, sleep deprivation, lack of social support and witnessing the suffering and dying of patients contribute to the challenges associated with the course (Dyrbye et al., 2005; Dyrbye et al., 2006). The effects of such stressors have also been described among Sri Lankan medical undergraduates (Lokuhetty et al., 2011; Jiffry et al., 2005). In spite of such challenges, students registered at the Faculty of Medicine, University of Colombo (FoM, UoC) perform well during their course, with low attrition rates of $0.5-1 \%$ per year, $75-80 \%$ pass rates at first attempt of the final MBBS examination and significant proportions (15$22 \%$ ) being placed among the first 100 in the Common Order of Merit of the UGC (de Abrew et al., 2015; UGC, 2013-2016). Graduates from the FoM, UoC are more likely to enter postgraduate training programmes, including higher degree programmes, take shorter time to complete their postgraduate training and are likely to pass the terminal examinations in their first attempt (de Abrew et al., 2015; UGC, 20132016).
The literature suggests that performance in medical school is affected by varied factors such as entrance examination scores, personality, gender, English language ability, coping skills and availability of academic and social support (Abdulghani et al., 2014; Hewage et al., 2011; De Silva et al., 2006, Ferguson et al., 2002).

\section{Objectives}

The objective of the present study was to develop a baseline database in order to generate a student profile and quantify selected factors that may predict academic performance among medical undergraduates.

\section{Methods}

A descriptive cross-sectional study was carried out among all students entering the Faculty of medicine, Colombo, on the basis of the General Certificate of Education (GCE) Advanced Level examination held in 2014. During the first term, a structured self-administered questionnaire was used to collect data on the following variables.

1. Demographic characteristics

2. Academic performance

3. Participation in extra-curricular activities

4. Residence and travel to the Faculty

5. Mobile phone and IT access

6. Self-reported proficiency in English

7. Self-reported proficiency in computer use

Data was analysed using Microsoft Excel 2013 for Windows. Data was described using descriptive statistics.

\section{Results}

A total of 198 students registered for the MBBS course, including eight admitted under foreign quota; four of these were from Bhutan. Details are summarized in Figures 1 and 2.

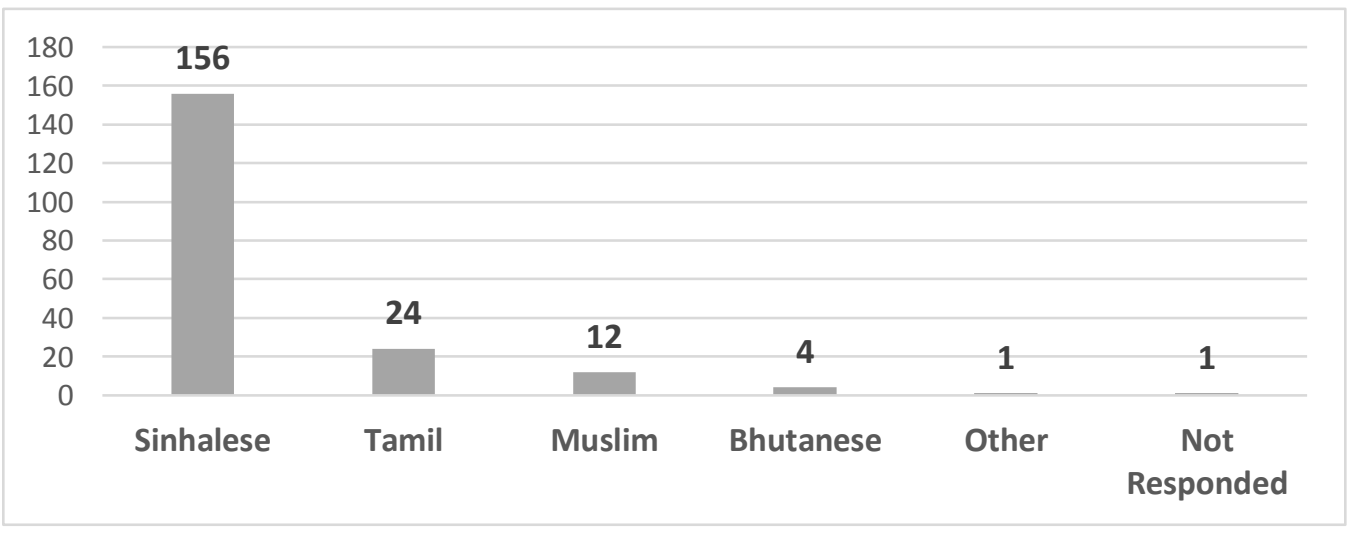

Figure 1: Ethnicity of the new students 


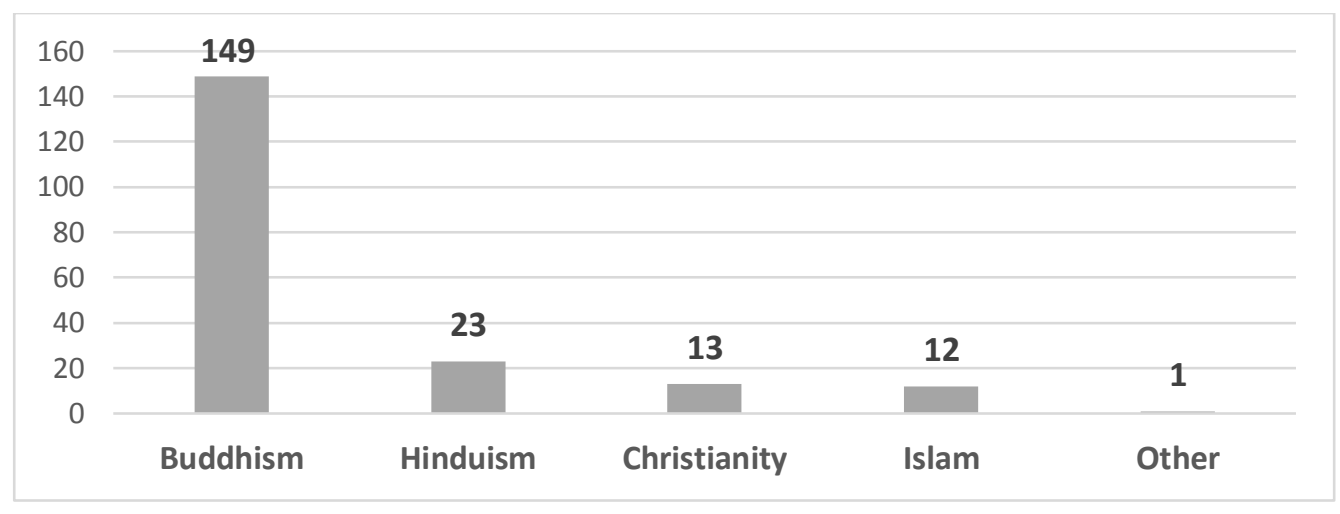

Figure 2: Religious background of the new students

The batch has a female preponderance (55\%), with the average age being 20.1 years (minimum=17; maximum=22). Students were predominantly Sinhalese and Buddhist. Majority have studied in their first language, however, just over $10 \%(n=20)$ have sat for the GCE Advanced Level (AL) examination in the English medium.

Most students (63\%, $\mathrm{n}=124)$ had entered on their first attempt at the GCE Advanced levels, which is the Ministry of Education entrance examination, with $31 \%$ gaining entry at the $2^{\text {nd }}$ attempt and $6 \%$ being private candidates entering on their $3^{\text {rd }}$ attempt. University admission in Sri Lanka is based on calculated Z-score values, with student selection based both on merit and on a district based quota. Z-scores indicated that all enrolled Sri Lankan students to the Faculty have entered on merit. The mean Z-score was 2.3833 with a minimum of 2.2 and a maximum of 2.9443. The number of entrants from each district and the minimum Z-score obtained from entrants in each district are summarized in Table 1.

Table 1: District wise summary of entrants

\begin{tabular}{lccc}
\hline District & $\begin{array}{c}\text { District level Z- } \\
\text { score cut off }\end{array}$ & $\begin{array}{c}\text { Number of } \\
\text { entrants }\end{array}$ & $\begin{array}{c}\text { Minimum Z- } \\
\text { score }\end{array}$ \\
\hline Ampara & 1.7558 & & \\
Anuradhapura & 1.6450 & 1 & 2.2218 \\
Badulla & 1.7189 & 2 & 2.4774 \\
Batticaloa & 1.7242 & 2 & 2.3954 \\
Colombo & 1.9370 & 6 & 2.2270 \\
Galle & 1.8820 & 21 & 2.2270 \\
Gampaha & 1.8194 & 13 & 2.2203 \\
Hambantota & 1.8294 & 2 & 2.2356 \\
Jaffna & 1.9096 & 9 & 2.2210 \\
Kalutara & 1.8465 & 7 & 2.2695 \\
Kandy & 1.8874 & 2 & 2.2321 \\
Kegalle & 1.8241 & 3 & 2.2000 \\
Kilinochchi & 1.7227 & 1 & 2.2533 \\
Kurunegala & 1.8578 & 11 & 2.2769 \\
Mannar & 1.5124 & 0 & 2.2362 \\
Matale & 1.7330 & 1 & \\
Matara & 1.8635 & 20 & 2.5638 \\
Monaragala & 1.4679 & 0 & 2.2269 \\
Mullaitivu & 1.4961 & 0 & \\
Nuwara Eliya & 1.4784 & 1 & - \\
Polonnaruwa & 1.6837 & 2 & 2.2216 \\
Puttalam & 1.7364 & 2 & 2.3189 \\
Ratnapura & 1.7703 & 6 & 2.2270 \\
Trincomalee & 1.7313 & 3 & 2.2270 \\
Vavuniya & 1.8603 & 3 & 2.2511 \\
\hline
\end{tabular}


All entrants had a Z-score above the cut-off score for the Colombo District (1.9370). The highest number of students $(n=72)$ entered from the Colombo District, while 21 and 20 students entered from the Southern Districts of Galle and Matara. Only 44 students (22\%) were permanently resident in the Colombo District. Close to $2 / 3$ rds reside at a private boarding place or with friends/relatives. Almost $60 \%$ stay within $5 \mathrm{~km}$ of the Faculty. Most either walk or travel by bus (Table 2).

Table 2: residence, distance from and transport to the Faculty

\begin{tabular}{lrc}
\hline Variable & Number & Percentage (\%) \\
\hline Place of residence & & \\
$\quad$ Home & 71 & 35.8 \\
Private boarding place & 106 & 53.5 \\
With relative/friend & 16 & 8.1 \\
Other & 4 & 2.1 \\
$\quad$ No response & 1 & 0.5 \\
Distance from residence to Faculty & & \\
$<1 \mathrm{~km}$ & 58 & \\
1-5 km & 55 & 29.3 \\
6-10 km & 29 & 27.7 \\
>10km & 54 & 14.6 \\
No response & 2 & 27.3 \\
Method of travel to the Faculty & & 1.0 \\
Bus & & \\
Private vehicle & 90 & \\
Train & 20 & 45.5 \\
Walking & 11 & 10.0 \\
Other & 74 & 5.6 \\
$\quad$ No response & 1 & 37.4 \\
& 2 & 0.5 \\
\end{tabular}

Close to half $(42 \%)$ reported participating in extra-curricular activities during the $\mathrm{AL}$ period. While for the most part this was involvement in various clubs and societies, some had been involved in debating, scouting, cadetting, quiz teams, dancing, music etc. Only about 30 students $(15 \%)$ had been involved in sports while at school. These sports were as diverse as swimming, athletics, basketball, table tennis, chess, cricket, carom, football, volleyball and squash. About $15 \%$ had engaged in some form of employment prior to entry to the Faculty. These included work in banks and insurance companies as interns, provision of $\mathrm{AL}$ tuition/assisting $\mathrm{AL}$ tuition teachers and teaching in secondary school. Details are summarized in Figure 3.

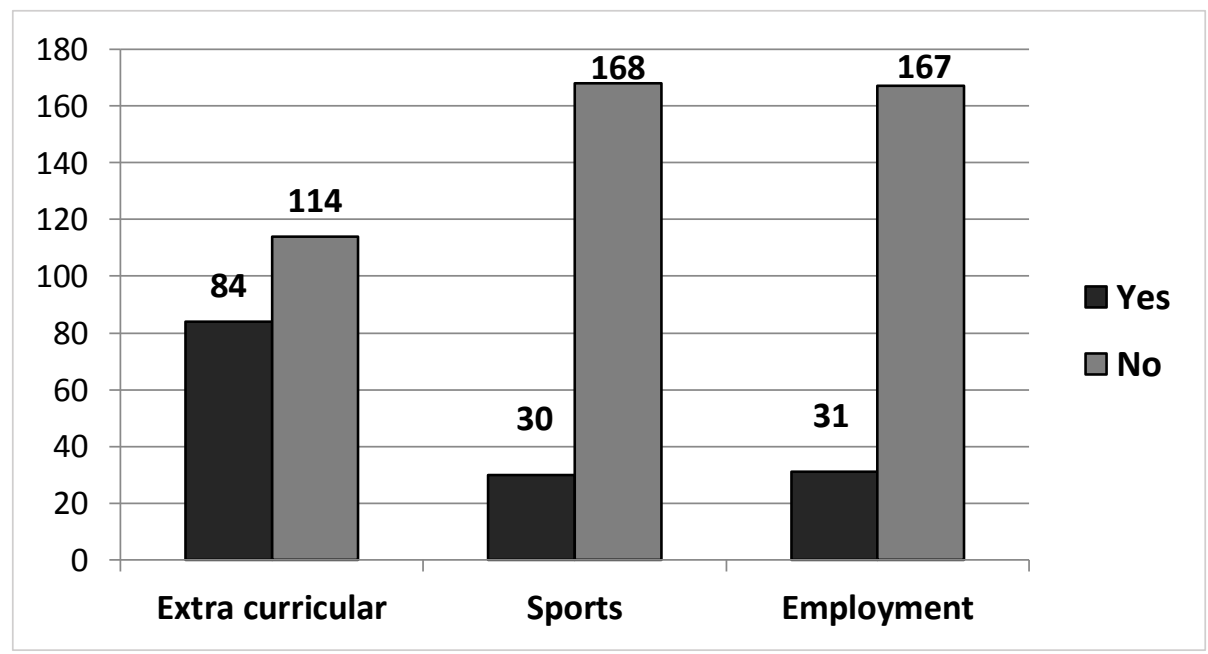

Figure 3: sports and other activities 
Almost all students have a phone (99\%) and most (89\%) have a smartphone. Not all have access to IT tools such as personal computers and broadband internet, with 17 students (9\%) lacking any access to personal computers or to broadband internet from the place they stay while attending Faculty
(Figure 4). Student's self-reported ability in key IT skills is summarized in Figure 5 . While close to half $(n=91)$ had attended a formal computer course, most showed a degree of independent learning as they had learnt essential IT based skills by themselves $(n=175)$ or from friends/family $(n=146)$.

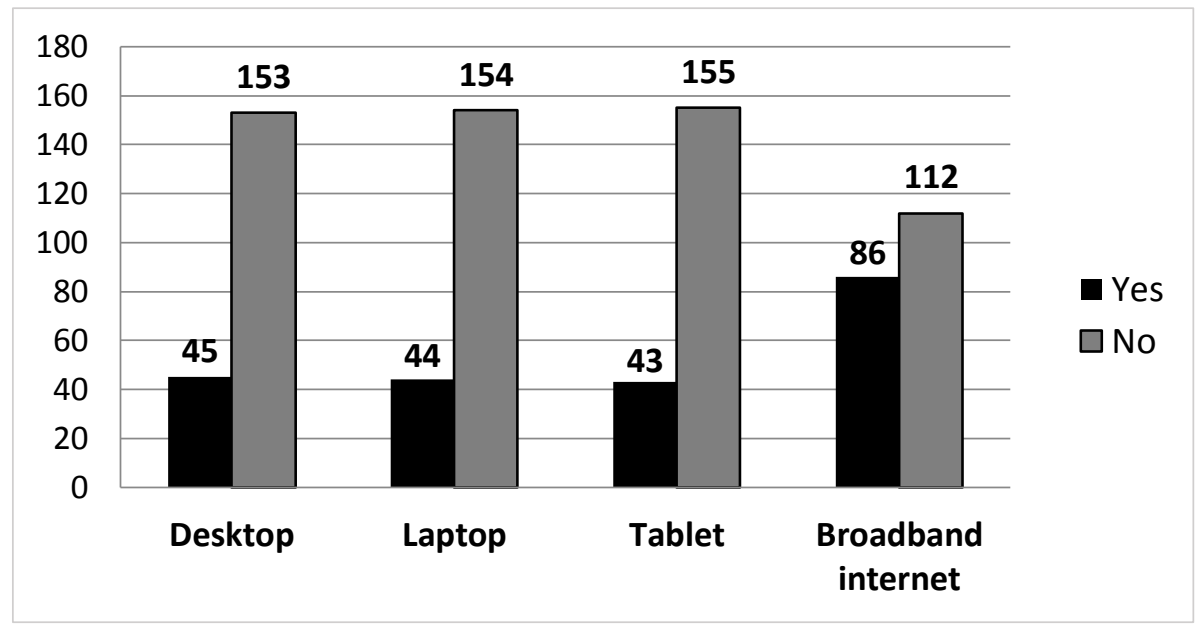

Figure 4: Access to IT

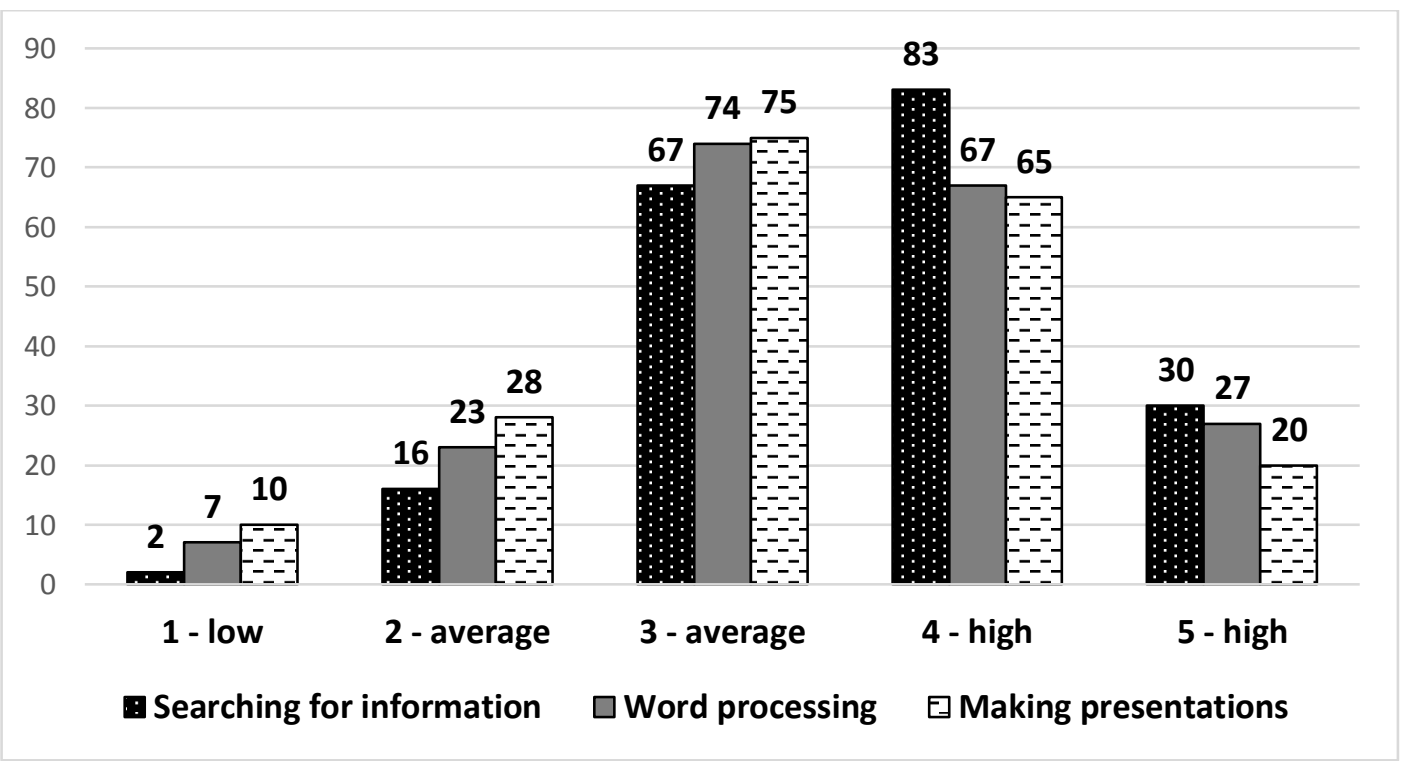

Figure 5: Self-reported IT Skills

Of the Sri Lankan students, the majority $(59 \%, n=117)$ had scored " $A$ " grades in the General English subject of the GCE Advanced Levels. Self-reported ability in key English Language skills are summarized in
Table 3 . While reading and writing skills were on average reported to be better, most students perceived that they had comparatively lower competency in listening to and understanding English. 
Table 3: Self-reported skills in English

\begin{tabular}{|c|c|c|c|c|c|}
\hline \multirow{3}{*}{ Competency } & \multicolumn{5}{|c|}{ Self-reported ability } \\
\hline & \multirow{2}{*}{$\frac{\text { Low }}{1}$} & \multicolumn{2}{|c|}{ Average } & \multicolumn{2}{|c|}{ High } \\
\hline & & 2 & 3 & 4 & 5 \\
\hline $\begin{array}{l}\text { Reading (how well can you read and } \\
\text { understand) }\end{array}$ & 0 & $\begin{array}{c}32 \\
(16.2 \%)\end{array}$ & $\begin{array}{c}84 \\
(42.4 \%)\end{array}$ & $\begin{array}{c}53 \\
(26.8 \%)\end{array}$ & $\begin{array}{c}29 \\
(14.6 \%)\end{array}$ \\
\hline Writing (how good is your writing) & $\begin{array}{c}4 \\
(2 \%)\end{array}$ & $\begin{array}{c}45 \\
(22.7 \%)\end{array}$ & $\begin{array}{c}84 \\
(42.4 \%\end{array}$ & $\begin{array}{c}48 \\
(24.2 \%)\end{array}$ & $\begin{array}{c}17 \\
(8.6 \%)\end{array}$ \\
\hline $\begin{array}{l}\text { Speech (how well can you express your } \\
\text { ideas) }\end{array}$ & $\begin{array}{c}2 \\
(1 \%)\end{array}$ & $\begin{array}{c}29 \\
(14.6 \%)\end{array}$ & $\begin{array}{c}78 \\
(39.4 \%)\end{array}$ & $\begin{array}{c}60 \\
(30.3 \%)\end{array}$ & $\begin{array}{c}29 \\
(14.6 \%)\end{array}$ \\
\hline $\begin{array}{l}\text { Listening (how well can you understand } \\
\text { what's being said) }\end{array}$ & $\begin{array}{c}25 \\
(12.6 \%)\end{array}$ & $\begin{array}{c}59 \\
(29.8 \%)\end{array}$ & $\begin{array}{c}80 \\
40.4 \%\end{array}$ & $\begin{array}{c}22 \\
(11.1 \%)\end{array}$ & $\begin{array}{c}12 \\
(6.1 \%)\end{array}$ \\
\hline
\end{tabular}

\section{Discussion}

This baseline study was conducted in order to develop a profile of new entrants to the Faculty of Medicine, Colombo and to quantify selected factors which may predict academic performance in the undergraduate medical degree programme.

\section{Demographic factors}

A total of 198 students were registered in the batch under study, of which $8(4 \%)$ were enrolled under the foreign student quota. The average age was 22.1 years, and there was a female preponderance of $55 \%$, which is reflective of the gradual feminization of Medicine as a career, both globally and in Sri Lanka. (de Silva et al., 2006; BuddebergFischer et al., 2006) In spite of the challenges in medical training, female medical students tend to outperform their male counterparts and female gender has been described as a significant predictor of success in medical school. (de Silva et al., 2006; Ferguson et al., 2002; Buddeberg-Fischer et al., 2006)

While the entrants were predominantly Sinhalese and Buddhist, as a whole, the ethnic and religious makeup of the batch reflects the multiculturalism of Sri Lankan society. The effect of ethnic/religious background as a factor affecting performance in medical school is not well described. While evidence seems to suggest more challenges among ethnic minorities these studies should be interpreted with caution until more locally relevant data is available. (Ferguson et al., 2002; Yates \& James, 2007).
In the present study, although over one third $(n=72)$ entered from the Colombo District, only 44 were permanent residents of Colombo. Over $60 \%$ reside at private hostels or with friends/relatives, usually within $5 \mathrm{~km}$ of the Faculty, while a few commute on a daily basis from homes over $10 \mathrm{~km}$ away. Family and social support have been reported to be associated with less adjustment problems, better emotional well-being and perceived better performance. (Abdhulghani et al., 2014; Laacina, 2002) Students living in dormitories, "off campus", rural students and international students report higher levels of anxiety and depression and resulting poor performance (Lacina, 2002; Qamar et al., 2015; Beiter et al., 2015; Ranasinghe et al., 2012; Bayram \& Bilgel, 2008). While there is little published data in the Sri Lankan context, anecdotal evidence suggests that medical students from rural areas and those living in private hostelsmayhave adjustment problems and challenges in academic performance.

\section{Previous academic performance}

All students have shown excellent academic performance during the GCE Advanced Level examination, which is the de facto medical school entrance examination in Sri Lanka. Disparities in secondary school education in the Government sector have led to a District based system for converting student performance into a standardized Z-score with District level cut-offs. Up to $40 \%$ of admissions to study medicine are based on performance (merit), with the remaining $60 \%$ based on a District quota based on the population of each District, and the 
designation of being "educationally disadvantaged".

All Sri Lankan entrants to the Colombo Medical Faculty have been selected on merit and had a Z-score above the cut-off score for the Colombo District. Foreign entrants too have demonstrated high subject and aggregate scores at GCE Advanced Level or equivalent examinations. Systematic reviews have reported that previous academic performance (e.g. entrance examination scores, grade point averages) are moderate predictors of success, and may account for up to $23 \%$ of the variance in performance during undergraduate training (Ferguson et al., 2002; Buddeberg-Fischer et al., 2006; de Silva et al., 2000, Yates \& James, 2007) Similarly, Sri Lankan researchers report that previous academic performance as quantified by Z-score and attempt at the Advanced Level examination as predictors of success. (de Silva et al., 2006).

\section{Extracurricular activities and work experience}

Sports and other extra-curricular activities and work experience, especially in a field related to science or health are looked upon favourably during admission to medical schools overseas. (Ferguson et al., 2002; McManus, 1998) During medical school, continuation of these activities have been reported to increase resilience, reduce stress and burn-out. (McManus, 1998; Yusoff et al., 2012) It is encouraging that $42 \%$ of the new entrants reported participation in some type of extra-curricular activity while in secondary school. Students should be encouraged to participate in the many student societies, clubs and teams at different levels.

\section{English language skills}

The Colombo Curriculum is delivered in the English language, and this transition can pose difficulty to students, of whom $90 \%$ completed their secondary school education in either Sinhalese or Tamil. Most students $(n=117)$ had obtained an "A" pass at the General English examination, a previously reported predictor of success. (Hewage et al., 2011; de Silva et al., 2006; Ranasinghe et al., 2012) Most reported average or high abilities in the four domains of the English language, although more students reported difficulty in listening comprehension, which would be a disadvantage during lectures. Students who are "low" academic performers are more likely to report poorer competencies in English. (Ranasinghe et al., 2012) Support should be provided to students through Language Laboratories and the University English Language Teaching Units in order to modify this "risk factor" for poor performance.

\section{Mobile connectivity, internet \& IT access}

In keeping with advances in information and communication technology (ICT) there is increasingly widespread use of mobile devices in order to facilitate information gathering and communication. Almost all students had a mobile phone while the vast majority $(89 \%)$ had a smartphone. While there was less access to other portable devices and broadband internet, there is vast potential for the use of technology in medical education. Availability of free Wi-Fi in student areas, access to the computer assisted learning laboratory and utilization of the online Learning Management System would encourage students to use them to support their learning.

Most students reported high levels of ability to perform identified simple IT based tasks such as making a basic PowerPoint presentation or searching for information online. However, there is a small but significant minority who lack even these basic skills. There may be a need for a basic IT course to encourage such skill development.

\section{Other factors that may affect performance}

Non-cognitive factors such as personality, approaches to learning and curricular factors such as the educational environment are also known to affect academic performance. Previous research on study skills and approaches to learning among undergraduates of the Colombo Medical Faculty have shown multi-modal learning preferences and strategic approaches towards learning. (Hassan et al., 2014; Samarakoon et al., 2013; Wickramasinghe \& Samarasekara et al., 2011) A study on noncognitive characteristics among students at the Faculty of Medical Sciences, University of Sri Jayewardenepura revealed the potential of certain personality and character traits such as self-appraisal, leadership and confidence to predict academic performance. (Ranasinghe et al., 2012). 
There is a need to further explore these factors and determine the validity, reliability and utility of using these not only to predict academic success, but also to identify those who may be struggling and offer early counselling and remedial interventions.

\section{Conclusion}

Entrants to the Faculty of Medicine, Colombo as a population demonstrate high rates of conventionally recognised predictors of academic success - high performance at GCE Advanced Level examination, majority entering at $1^{\text {st }}$ or $2^{\text {nd }}$ attempt, and satisfactory English language skills. There is a need to explore the use of these and other noncognitive factors to identify students who may be at risk of poor academic performance and offer early remedial intervention.

\section{Acknowledgements}

We wish to acknowledge the students for their cooperation in providing these baseline data and staff of the Department of Medical Education, Faculty of Medicine, Colombo for providing technical support.

\section{References}

Abdulghani, H.M., Al-Drees, A.A. \& Khalil, M.S. (2014) What factors determine academic achievement in high achieving undergraduate medical students? A qualitative study, Medical Teacher, 36, Suppl 2, S43-S48.

Bayram, N. \& Bilgel, N. (2008) The prevalence and socio-demographic correlations of depression, anxiety and stress among a group of university students, Social Psychiatry \& Psychiatric Epidemiology, 43, 8, pp. 667672.

Beiter, R., Nash, R. \& McCrady, M. (2015) The prevalence and correlates of depression, anxiety, and stress in a sample of college students, Journal of Affective Disorders, 173, pp. 90-96.

Buddeberg-Fischer, B., Klaghofer, R. \& Abel, T. (2006) Swiss resident's speciality choices impact of gender, personality traits, career motivation and life goals, BMC Health Services \& Research, 6, p. 137.

De Abrew, A., Hettihewa, A.P. \& Karunathilake, I.M. (2015) Tracer study of early career graduates of a selected cohort of the Faculty of Medicine, University of Colombo, In: Proceedings of the Annual Research Symposium, University of Colombo, Colombo, Sri Lanka, p. 82.
De Silva, N.R., Pathmeswaran, A. \& De Silva, N. (2006) Admission to medical schools in Sri Lanka: predictive validity of selection criteria, Ceylon Medical Journal, 51, 1, pp. 17-21.

De Silva, N.R., Thabrew, M.I. \& Saparamadu, P.A.M. (2000) Gender differences in undergraduate medical examination results in Sri Lanka, Ceylon Medical Journal, 45, 3, pp. 119-122.

Dunn, L.B., Iglewicz, A. \& Moutier, C. (2008) A conceptual model of medical student wellbeing: promoting resilience and preventing burnout, Academic Psychiatry, 32, 1, pp. 4453.

Dyrbye, L.N., Thomas, M.R. \& Shanafelt, T.D. (2005) Medical student distress: causes, consequences, and proposed solutions, Mayo Clinic Proceedings, 80, 12, pp. 1613-1622.

Dyrbye, L.N., Thomas, M.R. \& Shanafelt, T.D. (2006) Systematic Review of Depression, Anxiety, and Other Indicators of Psychological Distress Among U.S. and Canadian Medical Students, Academic Medicine, 81, 4, pp. 354373.

Faculty of Medicine, Colombo (2016) Undergraduate Degree Programme Handbook, Colombo: Faculty of Medicine, pp. 86.

Ferguson, E., James, D. \& Madeley, L. (2002) Factors associated with success in medical school: systematic review of the literature, British Medical Journal, 324, 7343, pp. 952957.

Goonasekera, C.D.A., Sheriff, M.H.R. \& Amarakoon, P.M. (2013) Does the undergraduate medical school influence postgraduate performance of doctors in Sri Lanka? An observational study, Indian Journal of Higher Education, 4, 2, pp. 98-106.

Guthrie E., Black D. \& Bagalkote H. (1998) Psychological stress and burnout in medical students: A five-year prospective longitudinal study, The Journal of the Royal Society of Medicine, 91, 5, pp.237-243.

Hassan, F., Olupeliyawa, A. \& Karunathilake, I.M. (2014) Patterns of Change in Approaches to Learning during Transition from School to Undergraduate Medical Education, In: Proceedings of the 11th Asia Pacific Medical Education Conference, Yong Loo Lin School of Medicine, National University of Singapore, Singapore, pp. 243.

Hewage, S.N., Salgado, L.S.S. \& Fernando, G.M.O. (2011) Selection of medical students in Sri Lanka: time to re-think criteria, Ceylon Medical Journal, 56, 1, pp. 22-28. 
Jiffry M.T.T., McAleer, S. \& Fernando, S. (2005) Using the DREEM questionnaire to gather baseline information on an evolving medical school in Sri Lanka, Medical Teacher, 27, 4, pp. 348-352.

Lacina, J.G. (2002) Preparing international students for a successful social experience in higher education, New Directions for Higher Education, pp. 21-28.

Lokuhetty, M.D., Warnakulasuriya, S.P. \& Perera, R.I. (2011) Students' perception of the educational environment in a Medical Faculty with an innovative curriculum in Sri Lanka, South-East Asian Journal of Medical Education, 4, 1, pp. 9-16.

McManus, I.C. (1998) Factors affecting likelihood of applicants being offered a place in medical schools in the United Kingdom in 1996 and 1997: retrospective study, British Medical Journal, 317, pp. 1111-1116.

Qamar, K., Khan, N.S. \& Bashir, K.M. (2015) Factors associated with stress among medical students, The Journal of the Pakistan Medical Association, 65, 7, pp. 753-755.

Ranasinghe, P., Ellawela, A. \& Gunatilake, S.B. (2012) Non-cognitive characteristics predicting academic success among medical students in Sri Lanka, BMC Medical Education, 12, 1, p. 66.

Samarakoon, L., Fernando, T. \& Rodrigo, C. (2013) Learning styles and approaches to learning among medical undergraduates and postgraduates, BMC Medical Education, 13, 1, pp. 42.

University Grants Commission, Sri Lanka, Merit order list of MBBS Graduates for Internship
Appointments; 2013-2016, Colombo: University Grants Commission.

University Grants Commission, Sri Lanka. (2004) Subject Benchmark Statement in Medicine Colombo: UGC, pp.12 [Internet] Available at: http://www.eugc.ac.lk/qaa/wp-content /uploads/2016/05/SBS_Medicine.pdf [Accessed 25th August 216].

University of Colombo. (2008) University History: A Glimpse into the History of the Oldest Medical School in Sri Lanka. University of Colombo Newsletter, 1, 2, pp. 2 [Internet] Available at: http://www.cmb.ac.lk/wpcontent/uploads/UoC-Newsletter-Vol-1-No-22008.pdf [Accessed 13th August 2016].

Waghachavare, V.B., Dhumale, G.B. \& Kadam, Y.R. (2013) A Study of Stress among Students of Professional Colleges from an Urban area in India, Sultan Qaboos University Medical Journal, 13, 3, pp. 429436.

Wickramasinghe, D.P. \& Samarasekera, D.N. (2011) Factors influencing the approaches to studying of preclinical and clinical students and postgraduate trainees, BMC Medical Education, 11, pp. 22.

Yates J. \& James D. (2007) Risk factors for poor performance on the undergraduate medical course: cohort study at Nottingham University, Medical Education, 41, 1, pp. 6573.

Yusoff, M.S.B., Rahim, A.F.A. \& Baba, A.A. (2013) Prevalence and associated factors of stress, anxiety and depression among prospective medical students, Asian Journal of Psychiatry, 6, 2, pp.128-133. 